\title{
Reflexões sobre processos de constituição do movimento indígena no Baixo Tapajós a partir de narrativas femininas
}

\section{Reflexiones sobre procesos de constitución del movimiento indígena en el Bajo Tapajós a partir de narrativas femeninas}

\author{
Luana Lazzeri Arantes ${ }^{1}$
}

\begin{abstract}
Resumo: Proponho nesse artigo refletir sobre processos de constituição do movimento indígena na região do Baixo rio Tapajós, no Oeste do Estado do Pará. O levantamento de material foi realizado com base em pesquisa bibliográfica e entrevistas com mulheres dos povos Arapium, Borari, Kumaruara, Maytapu e Tapajó que atuam no movimento indígena. Inicialmente, apresento um panorama da institucionalização do movimento indígena no Brasil para, então, a partir de acontecimentos narrados pelas mulheres indígenas que entrevistei, evidenciar processos sociais específicos construídos por elas no sentido de mediar diferentes universos, orientar a ação política do movimento indígena e efetivar o desejo de manter uma identidade específica.
\end{abstract}

Palavras-chave: movimento Indígena, mulheres indígenas, mediação social, Baixo Tapajós.

\begin{abstract}
En este artículo se reflexionan sobre procesos de constitución del movimiento indígena en la región del Bajo río Tapajós, en el Oeste del Estado de Pará. El levantamiento de material fue realizado con base en investigación bibliográfica y entrevistas con mujeres de los pueblos Arapium, Borari, Kumaruara, Maytapu y Tapajó que actúan en el movimiento indígena. En primer lugar, presento un panorama de la institucionalización del movimiento indígena en Brasil para entonces, a partir de acontecimientos narrados por las mujeres indígenas que entreviste, evidenciar procesos sociales específicos construidos por ellas en el sentido de mediar diferentes universos, orientar la acción política del movimiento indígena y efectivizar el deseo de mantener una identidad específica.

Keywords: movimiento indígena, mujeres indígenas, mediación social, Bajo Tapajós.
\end{abstract}

\section{Introdução}

A reflexão aqui apresentada é parte minha pesquisa de doutorado em andamento que busca investigar a construção das relações interculturais e dos processos de mediação social entre mulheres indígenas do Baixo Tapajós que circulam em diferentes universos sociais, no caso, territórios tradicionais indígenas e território universitário e urbano. Para convergir com a temática proposta para esse dossiê, o foco aqui será evidenciar, a

\footnotetext{
${ }^{1}$ Doutoranda no Programa de Pós-Graduação Sociedade, Natureza e Desenvolvimento/Ufopa, Mestre em Antropologia/UnB. Contato: luana.larantes@gmail.com
} 
partir das narrativas de mulheres representantes de cinco dos treze povos indígenas da região, o processo de constituição do movimento indígena. Na perspectiva de contribuir com o debate sobre os sentidos e significados do termo nativo movimento indígena, na primeira parte levanto algumas questões sobre a institucionalização do chamado movimento indígena no Brasil. Na sequência, discorro sobre a constituição do movimento indígena no Baixo Tapajós.

\section{Institucionalização do Movimento Indígena no Brasil}

A categoria nativa movimento indígena é central no discurso dos/as indígenas e de seus interlocutores de modo geral (representantes de Estado, de organizações nãogovernamentais, pesquisadores/as). A ideia predominante é que os povos indígenas "precisam realizar uma mobilização política, compondo mecanismos de representação, estabelecendo alianças e levando seus pleitos à opinião pública" (PACHECO DE OLIVEIRA, 2016, p. 275), pois é necessário constituir um "sistema de pressões" para o Estado demarcar terras, melhorar os serviços de assistência à saúde e educação (idem). Esse sistema de pressão, na concepção de representantes do movimento indígena , deve ser articulado e liderado exclusivamente pelos/as indígenas.

O termo "indígenas" tornou-se uma categoria política que os povos assumiram, a partir dos anos 1970, para marcar diferença étnica e identitária deles enquanto habitantes nativos em relação àquelas pessoas e seus descendentes que vieram de outros continentes (LUCIANO, 2006, p. 30). A categoria também passou a ser acionada por essas populações para demarcar a sua relação com políticos e representantes do Estado brasileiro. Originalmente, o termo índio ou indígena foi usado pelos portugueses quando chegaram ao Brasil, no século XVI, para classificar a população nativa, pois eles achavam que estavam chegando à Índia. Por séculos, foi uma nomeação dos não-indígenas para os povos nativos sendo utilizada, com muita recorrência, de modo pejorativo, a partir do ponto de vista que os índios eram selvagens, sem civilização, preguiçosos e incapazes (idem). Mas, como mencionado, essa categoria foi ressignificada por lideranças dos povos originários no processo de organização política dessas populações nativas frente às classes políticas dominantes. Essa organização política é denominada, por esses povos, movimento indígena . 
Gersem José dos Santos Luciano no livro "O índio brasileiro: o que você precisa saber sobre os povos indígenas no Brasil de hoje" (2006), propõe um conceito de movimento indígena. Gersem Luciano é do povo Baniwa, que vive no Alto rio Negro no noroeste do estado do Amazonas. Ele é doutor em Antropologia pela Universidade de Brasília (UnB), professor da Faculdade de Educação e Diretor de Políticas Afirmativas da Universidade Federal do Amazonas (UFAM), é conselheiro do Conselho Nacional de Educação, foi professor em escola indígena, gestor de políticas educacionais na Prefeitura Municipal de São Gabriel da Cachoeira/AM e no Ministério da Educação. Na esfera do movimento indígena, atuou na Federação das Organizações Indígenas do Rio Negro (FOIRN), na Coordenação das Organizações Indígenas da Amazônia Brasileira (COIAB) e foi Diretor-Presidente do Centro Indígena de Estudos e Pesquisas (CINEP). Ou seja, Gersem Luciano ocupa uma posição social de mediação entre diferentes mundos: aldeia, instituições públicas, universidade e movimento indígena. A partir dessa experiência de mediação social (NEVES, 2008), a proposta de Gersem Luciano é conceituar movimento indígena tomando como referência o entendimento nativo, ou seja, dos/as próprios/as indígenas:

Movimento indígena, segundo uma definição mais comum entre as lideranças indígenas, é o conjunto de estratégias e ações que as comunidades e as organizações indígenas desenvolvem em defesa de seus direitos e interesses coletivos. Movimento indígena não é o mesmo que organização indígena, embora esta última seja parte importante dele. Um indígena não precisa pertencer formalmente a uma organização ou aldeia indígena para estar incluído no movimento indígena, basta que ele comungue e participe politicamente de ações, aspirações e projetos definidos como agenda de interesse comum das pessoas, das comunidades e das organizações que participam e sustentam a existência do movimento indígena (...).

O líder indígena Daniel Mundurucu costuma dizer que no lugar de movimento indígena dever-se-ia dizer índios em movimento. Ele tem certa razão, pois não existe no Brasil um movimento indígena. Existem muitos movimentos indígenas, uma vez que cada aldeia, cada povo ou cada território indígena estabelece e desenvolve o seu movimento. Mas as lideranças indígenas brasileiras, de forma sábia, gostam de afirmar que existe sim um movimento indígena, aquele que busca articular todas as diferentes ações e estratégias dos povos indígenas(...).Essa visão estratégica de articulação nacional não anula nem reduz as particularidades e a diversidade de realidades socioculturais dos povos e dos territórios indígenas; ao contrário, valoriza, visibiliza e fortalece a pluralidade étnica, na medida em que articula, de forma descentralizada, transparente, participativa e representativa os diferentes povos.

No Brasil, existe de fato, desde a década de 1970, o que podemos chamar de movimento indígena brasileiro, ou seja, um esforço conjunto e articulado de lideranças, povos e organizações indígenas objetivando 
uma agenda comum de luta (...). Foi esse movimento indígena articulado, apoiado por seus aliados, que conseguiu convencer a sociedade brasileira e o Congresso Nacional Constituinte a aprovar, em 1988, os avançados direitos indígenas na atual Constituição Federal (LUCIANO, 2006, p. 58-59).

Alguns elementos da definição de movimento indígena, elaborada por Luciano, merecem destaque como, por exemplo, a não necessidade de formalização de uma organização para que um/a indígena esteja incluído/a nesse sistema de representação. Assim, a legitimidade do movimento indígena não passa, necessariamente, por uma institucionalização burocrática. Saliento, também, a opção política das lideranças indígenas em defender a existência de um movimento indígena que representa todos os povos. Essa unicidade do movimento indígena, defendida pelas lideranças, é uma estratégia para tentar ampliar a influência no jogo de disputas entre atores sociais. De toda maneira, o discurso das representações indígenas é que o movimento é único, mas são centenas de povos diferentes entre si. O reconhecimento da pluralidade étnica da sociedade brasileira, ainda que explicitado na Constituição Federal, permanece como uma demanda recorrente das lideranças indígenas perante seus interlocutores/as não-indígenas.

Silva (2016) se propõe a revisar a bibliografia sobre movimento indígena na América Latina e demonstra como pesquisadores/as que trabalham com o tema negam o uso dos conceitos elaborados no âmbito das teorias sobre movimento sociais para analisar o movimento indígena. Segundo o autor, a especificidade do movimento indígena está na sua natureza política sui generis, principalmente por ter a ancestralidade como fundamento; e pela relação singular com o Estado Nacional, que se difere muito dos outros movimentos sociais. É relevante a passagem em que Silva (2016, p.162) apresenta reflexões de Monica Bruckmann (2011, p. 334) sobre o movimento indígena:

A partir de uma profunda crítica e ruptura com a visão eurocêntrica, sua racionalidade, seu modelo de modernidade e desenvolvimento inserido na estrutura do poder colonial, o movimento indígena latino-americano se coloca como um movimento civilizatório, capaz de recuperar o legado histórico das civilizações originais para reelaborar, não uma, mas várias identidades latino-americanas; não uma forma de produzir conhecimento, mas todas as formas de conhecimento e produto com que têm convivido e resistido à dominação há mais de quinhentos anos. O elemento indígena vai se convertendo no centro do discurso e da construção de uma visão de mundo, de um sujeito político e de um projeto coletivo e emancipador.

Nesse sentido, movimento indígena reúne visões de mundo específicas que se 
unificam em torno de um projeto coletivo. O tema aglutinador, no sentido de mobilizar e unificar os interesses de diferentes povos indígenas, ou seja, catalisador da organização do movimento indígena é o direito ao território tradicional.

O território indígena é sempre a referência à ancestralidade e a toda a formação cósmica do universo e da humanidade. É nele que se encontram presentes e atuantes os heróis indígenas, vivos ou mortos. (...) Para os povos indígenas, o território compreende a própria natureza dos seres naturais e sobrenaturais, onde o rio não é simplesmente o rio, mas inclui todos os seres, espíritos e deuses que nele habitam. (...) Terra e território para os índios não significam apenas o espaço físico e geográfico, mas sim toda a simbologia cosmológica que carrega como espaço primordial do mundo humano e do mundo dos deuses que povoam a natureza (LUCIANO, 2006, p. 101-102).

Ainda que o direito à terra tenha essa centralidade na articulação entre os povos indígenas, uma gama de outros temas também é pauta antiga do movimento, como, por exemplo, educação e saúde diferenciadas.

A partir da segunda metade do século $X X$, indígenas começaram a se articular para construção de condições institucionais de negociação de pautas de reivindicações, frente ao Estado brasileiro. De meados dos anos 1970 até meados dos anos 1980, as primeiras grandes assembleias indígenas foram realizadas. Inicialmente, elas foram organizadas e apoiadas por integrantes do Conselho Indigenista Missionário - CIMI. Essas assembleias reuniam indígenas de todo país. Foi nessa ocasião que muitos/as saíram pela primeira vez das redondezas de sua aldeia e enfrentaram desafios geográficos e culturais para chegar até ao local do encontro. A partir dessas assembleias, representantes de povos de diferentes regiões foram se conhecendo, entendendo quais eram as diferenças e semelhanças entre eles.

Assembleias de Chefes Indígenas representam o lugar onde as lutas são partilhadas, assim como os anseios, as frustrações, os medos, as necessidades, as esperanças, as conquistas, a cultura, os hábitos, os costumes, a indianidade enfim. (BICALHO, 2010, p. 94).

Bicalho (2010) analisou registros de 08 assembleias e em todas elas o tema da demarcação das terras indígenas foi preponderante. Essas mobilizações serviram para unir lideranças indígenas que começarem a se organizar politicamente para exigir institucionalização formal não apenas do direito à demarcação de suas terras, mas também da educação e saúde diferenciada e da autonomia de entrar em juízo em defesa de seus interesses. Surgia, aí, "um novo ator político e social (...) consciente da sua cultura, da 
sua história e da necessidade de mobilização do grupo como meio de ruptura com a condição de colonizado" (BICALHO, 2010, p. 110). Por isso, o argumento central de Bicalho é que essas assembleias são, no sentido dado por Ricoeur, o acontecimento fundador do movimento indígena no Brasi ${ }^{2}$

Essas articulações culminaram na criação, em 1980, da União das Nações dos Indígenas - UNI e se fortaleceram com as mobilizações para o processo constituinte, em anos antecedentes a 1988. O referido processo marca a passagem do regime de ditadura militar no Brasil, iniciado em abril de 1964, para o regime democrático. No período da redemocratização do país, aconteceu a revisão da constituição com uma participação ativa de representantes da sociedade civil organizada. Nesse processo, porta-vozes de diversos setores marginalizados da sociedade denunciaram as desigualdades sociais, políticas e econômicas das quais eram vítimas e conseguiram que elas fossem reconhecidas como questões nacionais. Mais ainda, eles/as negociaram a garantia de direitos na constituição no sentido de reparar e frear os abusos por eles/as sofridos. A Constituição de 1988 ficou popularmente conhecida como a Constituição Cidadã. No caso específico dos/as indígenas, destaco a aprovação dos artigos n 231 e 232 da Constituição Federal que garantem (i) o reconhecimento de sua organização social, costumes, línguas, crenças e tradições, (ii) os direitos originários sobre as terras que tradicionalmente ocupam e (iii) a legitimidade para eles mesmos entrarem em juízo em defesa de seus direitos e interesses.

A Constituição de 1988 gerou consequências diversas na organização política dos povos indígenas. Uma delas foi impulsionar e consolidar o processo de surgimento e a existência legal de associações indígenas, ao reconhecer a capacidade civil dos/as índios/as e de suas organizações sociais e políticas. Assim, nos anos 1990, há um crescimento acelerado de criação dessas associações, tanto locais, quanto estaduais, regionais e nacionais. Em 1991, existiam 49 associações indígenas registradas; em 1999, esse número subiu para 290 (SOUZA LIMA, HOFFMANN, PERES, S/D). Em 2006, chegou-se a 700 associações indígenas formalizadas (LUCIANO, 2006, p. 67). Para lide-

\footnotetext{
${ }^{2}$ Bicalho (2010, p.95 -96), baseado em Ricouer, entende acontecimento fundador como um momento de ruptura e de conhecimento, que articula as noções de sincronia e diacronia, que representa marco simbólico e/ou real que produz reinterpretação de tradições, conduz ao ordenamento e à compreensão histórica. È constantemente atualizado e interliga passado-presente-futuro.
} 
ranças indígenas, criar organizações próprias para representar seus interesses significa a possibilidade de romper com a dependência de entidades não-indígenas para fazer a mediação com agentes, principalmente, que representam o Estado. Nesse sentido, é uma mudança na posição social que lideranças indígenas ocupavam até então, pois para serem legitimadas precisavam, necessariamente, de um/a mediador/a para representálas. De acordo com Luciano (2006), o principal objetivo dos povos indígenas ao criar essas entidades jurídicas é a defesa pela efetivação de seus direitos constitucionais diferenciados. Outro estímulo é a possibilidade de captar recursos financeiros para executar projetos de interesse dos/as moradores/as das aldeias e das lideranças.

Porém, gerir essas entidades após sua fundação é um desafio para a grande maioria dos/as indígenas, afinal:

O modelo de organização social, no formato de associação institucionalizada, não respeita o jeito de ser e de fazer dos povos indígenas. Os processos administrativos, financeiros e burocráticos, além de serem ininteligíveis à racionalidade indígena, confrontam e ferem os valores culturais dos seus povos, como o de solidariedade, generosidade e democracia. O modelo hierarquizado de uma diretoria de associação formal, por exemplo, além de criar conflitos de poder dentro da comunidade indígena, cria também diferenciações sociais e econômicas e fragiliza o valor da democracia horizontal, na qual o poder de decisão é um direito inalienável de todos os indivíduos e grupos que compõem a comunidade. (...) No entanto, é o único caminho para o acesso a recursos públicos ou da cooperação internacional. O desafio é como compatibilizar as diferentes lógicas, racionalidades e formas operacionais de tomada de decisão, de distribuição de bens e produtos, de organização das diferentes tarefas e responsabilidades, da noção de autoridade, de poder, de serviço e de representação política (LUCIANO, 2006, p. 82).

Essa reflexão de Luciano contribui para entendimento da situação das entidades representativas dos povos indígenas no Baixo Tapajós, pois uma das tensões recentes vividas pelos participantes do movimento indígena local é o método de escolha dos/as coordenadores/as do conselho que os representa, o CITA - Conselho Indígena Tapajós Arapiuns. A disputa se coloca exatamente na compatibilização das diferentes lógicas. Um grupo significativo de lideranças questionou o resultado da assembleia para eleger nova coordenação, realizada em fevereiro de 2018, na localidade de Pinhel, alegando que não se respeitou a lógica indígena subjacente a esta indicação e todo o processo foi orientado por uma lógica dos brancos. Em meio a um clima tenso, três meses depois foi realizada nova assembleia eletiva, dessa vez na cidade de Santarém. As pessoas 
eleitas nessa última ocasião tomaram posse e estão atuando no papel para o qual foram designadas. Mas, como era de se esperar, os conflitos no que se refere aos modos de representação, de atuação e de circulação nos diferentes espaços políticos permanecem. Representantes do movimento indígena no Baixo Tapajós problematizam a mediação entre esses mundos, principalmente nas relações de indígenas em circulação na cidade. No próximo tópico esse assunto será retomado.

Já no século XXI, em 2005, em Brasília, foi realizado o primeiro Acampamento Terra Livre - ATL, também conhecido como Mobilização Nacional Indígena. Desde então, acontece anualmente, cada vez com mais visibilidade e representatividade. $\mathrm{Na}$ ocasião do primeiro ATL foi criada a Articulação dos Povos Indígenas do Brasil - APIB, composta por 06 organizações indígenas regionais ${ }^{3}$. A APIB é uma entidade importante que, apesar de dificuldades de várias ordens, suas lideranças conseguiram construir legitimidade para representar os povos indígenas no Brasil e no mundo. A partir de diferentes estratégias, os porta-vozes do movimento indígena visam organizar as demandas em nível local, regional e nacional para reivindicar direitos territoriais e sociais dos quase 900 mil indígenas, pertencentes a 305 povos, falantes de 274 línguas que vivem no país (INSTITUTO BRASILEIRO DE GEOGRAFIA E ESTATÍSTICA, 2010). ]

\section{Movimento indígena no Baixo Tapajós}

Ao passo que a questão indígena foi se instituindo como uma questão nacional, de interesse público e que mobiliza diferentes agentes sociais, as lideranças ganharam legitimidade para articular maior número de indígenas para participar do movimento. Essa configuração de fatores expandiu a capacidade de mobilização e culminou na ampliação da rede indígena incidindo em todo território nacional, inclusive no Baixo Tapajós.

Na região do Baixo Rio Tapajós, a década de 1990 foi dedicada à mobilização para a criação da Reserva Extrativista (Resex) Tapajós-Arapiuns, a partir de inúmeros encontros intercomunitários envolvendo moradores/as das mais de 60 localidades à margem esquerda do Baixo rio Tapajós e às margens do rio Arapiuns. Inicialmente, a aliança

\footnotetext{
${ }^{3}$ São elas: Articulação dos Povos Indígenas do Nordeste, Minas Gerais e Espírito Santo - APOINME; Articulação dos Povos Indígenas do Pantanal e Região - ARPIPAN; Articulação dos Povos Indígenas do Sudeste - ARPINSUDESTE; Articulação dos Povos Indígenas do Sul - ARPINSUL; Grande Assembléia do povo Guarani - ATY GUASSÚ; Coordenação das Organizações Indígenas da Amazônia Brasileira - COIAB.
} 
do/as comunitários/as se deu para fortalecer o enfrentamento às madeireiras que se estabeleciam na margem esquerda do Tapajós e no Arapiuns. A mobilização entre moradores/as dessas localidades nessa época fervilhava. A luta pelo direito territorial unia as pessoas. Nas reuniões e assembleias se discutiam o significado do território e os motivos pelos quais a população local era a legítima dona da terra. Esse debate levava as pessoas a falarem sobre tradição, dos antepassados indígenas, das lutas para se manter no território tradicional, do significado da terra para seus habitantes. Nessa conjuntura, ocorreu uma valorização das narrativas das anciãs e anciãos para quem era solicitado que contassem histórias dos antigos. Essas histórias eram ouvidas com atenção e passaram a ser registradas para servir de prova que aquele território era habitado há muito tempo pelos antepassados dos/as moradores/as (VAZ FILHO, 2010).

Agentes sociais articuladores/as da criação da Resex ao escutarem narrativas sobre a constituição das localidades, as atividades produtivas desenvolvidas, o tipo de alimentação consumida e o sistema de crenças nos seres encantados incentivavam as pessoas a valorizarem essas referências culturais que, segundo esses agentes, remetiam às tradições indígenas. Nessa conjuntura que, em 1997, foi criado o Grupo Consciência Indígena - GCl. O grupo foi fundado por Florêncio de Almeida Vaz Filho - indígena do povo Maytapu, frei, professor universitário e antropólogo - junto com pessoas que compunham, naquele tempo, o Grupo de Reflexão de Religiosos Negros e Indígenas (GRENI) vinculado à Igreja Católica (VAZ FILHO, 2010, p. 308). Os representantes do GCI promoviam debates com comunitários/as sobre território e tradição, faziam rituais indígenas em torno da fogueira, propiciavam círculos de conversas regadas à tarubá e xibé - produtos oriundos da mandioca 4 . Os integrantes do CGI assumiram um papel político de incentivar os/as moradores/as da região ribeirinha no Baixo rio Tapajós a ressignificar o modo como eles/as se organizavam politicamente e assumiam uma identidade coletiva (VAZ, 2019). Assim, foi na conjuntura da luta pela criação da Resex Tapajós-Arapiuns que se deu processo de reafirmação da identidade indígena.

O GCI foi criado por pessoas que militavam no âmbito de entidades vinculadas à Igreja Católica. Essa trajetória é comum a vários/as militantes indígenas na região do

\footnotetext{
${ }^{4}$ Tarubá é uma bebida fermentada de mandioca e xibé é uma comida feita da mistura de farinha de mandioca com água. Ambas são de origem indígena e bastante consumidas na região.
} 
Baixo Tapajós. Muitas dessas pessoas iniciaram sua atuação política em ações coordenadas pela igreja. Por exemplo, Auricélia Arapium é oriunda da localidade de São Pedro, no rio Arapiuns, atual vice-coordenadora do CITA e acadêmica de Direito na Universidade Federal do Oeste do Pará - UFOPA ${ }^{5}$. Ela conta que começou a participar de movimento social acompanhando a mãe que era catequista da igreja.

A mamãe era catequista. Comecei a seguir os passos da minha mãe. Quando eu tinha 09 anos eu comecei a participar muito da igreja. A mamãe ia muito para as semanas catequéticas. Que é um encontro de formação anual dos catequistas. E eu sempre fui com a mamãe que eu era babá dos meus irmãos menores. (...) No ano de 1997, eu me recordo que eu tinha de 09 para 10 anos. Eu fui para a semana catequética no Curi. Eu fui babá de um dos meus irmãos menores. Aí apareceu o frei Florêncio lá na semana catequética e eu sempre ficava ali brechando, né? Aquela formação. Eu sempre ficava brechando, olhando para lá, olhando das brechas. Ai eu prestei atenção e começaram a cantar. Cantar numa roda assim. E começaram a cantar e a dançar. E era o "Xibé Puranga". Eu aprendi a música na hora e depois eu já estava cantando para o meu irmão. E ai foi a primeira vez que eu vi o Florêncio, foi a primeira vez que eu ouvi falar de movimento indígena. Foi nessa época. O Florêncio estava na semana catequética que ele era da Pastoral Social e também muito ligado ao movimento que estava se criando para criar a RESEX. De lá eu continuei na igreja, né? (Entrevista gravada em 21.06.2018, em Santarém/PA)

Auricélia Arapium iniciou sua militância no movimento indígena no final do ano 2000, quando pela primeira vez moradores/as de São Pedro participaram do "II Encontro dos Povos Indígenas do Tapajós e Arapiuns" realizado na aldeia São Francisco. Mas foi a partir do ano de 2001 que ela, ainda bem jovem, com catorze anos, começou a se envolver intensamente nas ações planejadas por lideranças das organizações indígenas, como eventos, reuniões, formações, viagens. Até o ano de 2008, Auricélia se dedicou às atividades do movimento indígena. No entanto, por um período de quatro anos ela se afastou e voltou a atuar em ações coordenadas por agentes da Igreja Católica.

Eu fui numa semana catequética (...). O pessoal me escolheu para ser secretária da área pastoral do Arapiuns. Ai vai a Auricélia para a igreja. E fiquei. Comecei a ficar andando, né? De um lado para o outro com o padre. E o coordenador na época era o pai do Edinei, que hoje é o coordenador do CITA. Eu me dou muito bem com ele porque a gente trabalhou junto, né? E a gente fazia formação nas comunidades. Nessa época foi que eu me endividei muito com o movimento indígena aqui. De 2008 para 2012. Eu fiquei mais para a igreja, mais para lá. Casei. Casei assim, né? Fiquei com ele. E fui dar aula. Então, foi o período que mais eu me afastei (Entrevista gravada em 21.06.2018, em Santarém/PA).

\footnotetext{
${ }^{5}$ Sobre o percurso de vida de Auricélia ver Arantes (2018).
} 
Outro exemplo é a trajetória da liderança Luana Kumaruara, oriunda da aldeia Solimões, na margem esquerda do rio Tapajós, atual Presidenta Distrital da Saúde Indígena no Baixo Tapajós e acadêmica de Antropologia na Ufopa $a^{6}$. Ela, diferente de Auricélia Arapium, começou a militar politicamente em causas sociais na cidade de Santarém. Mas, tal como Auricélia, iniciou sua atuação em organização vinculada à igreja católica.

Eu já atuava no Movimento Tapajós Vivo. Assim, tinha aquela CEB, né? Comunidade Eclesial de Base. Tinha a nossa lá no bairro da Floresta. Quando tinham os eventos assim de movimento social eles chamavam a gente para participar. E foi lá que eu conheci o padre Edilberto e ele disse "Ah, tem o Movimento Tapajós Vivo". E quando tinha os atos eu ia e fui me identificando com aquilo, né? E eu ia. Eu sempre ia. Quando eu entrei na Ufopa eu tenho contato com o Grupo Consciência Indígena. Ai eu conheci o Florêncio. Eu já sabia quem ele era quando eu fui para o GCI. (...) Aí eu fui para o Grupo Consciência Indígena que funcionava lá perto da Ufopa, né? Fim de semana tinha as reuniões e eles começaram a me chamar e eu chamava os colegas. Bora? (Entrevista gravada em 23.06.2018, em Santarém/PA).

A ação de agentes ligados a setores progressistas da igreja católica influenciou diretamente o processo de constituição do movimento indígena no Baixo Tapajós. No começo, principalmente, por meio da formação política de lideranças. Depois, as lideranças indígenas passaram a construir uma autonomia na ação política alicerçada na busca por reconhecimento social do direito à diferença, tanto em relação às pessoas não indígenas quanto em relação ao pertencimento a um determinado povo. Com o passar do tempo, representantes da igreja passaram a atuar mais pontualmente por meio, principalmente, de apoio logístico e financeiro na realização das ações do movimento indígena.

O papel desempenhado pelo $\mathrm{GCl}$, que como referido foi criado a partir de pessoas vinculadas à igreja, é presente nas narrativas das lideranças ao falar do processo inicial de articulação do movimento indígena na região do Baixo Tapajós. Militantes do GCl iam até as localidades na beira dos rios Tapajós e Arapiuns para reunir com moradores/as em volta de uma fogueira contar histórias dos antigos, fazer rituais, cantar, tomar tarubá. Esses encontros eram promovidos, a convite das lideranças comunitárias, e proporcionavam a construção de um entendimento coletivo das práticas e conhecimentos locais como heranças dos antepassados a serem valorizados. Aparentemente, parece um movimento simples, mas essas pessoas vivenciaram, ao longo de séculos, processos

\footnotetext{
${ }^{6}$ Após escrita desse texto, Luana Kumarura se formou em Antropologia na Ufopa e hoje está cursando mestrado em Antropologia na Universidade Federal do Pará - UFPA.
} 
violentos de opressão ao seu modo de existência. Nesse sentido, positivar suas origens e seu modo de viver é um ato revolucionário sobre o que significa ser/estar no mundo e produzir vida social.

Como explicitado, o GCl era - e ainda é - liderado pelo Florêncio Vaz que é um destacado agente de mediação social, pois ao mesmo tempo ocupa os papéis de indígena, frei, antropólogo, professor universitário e militante. A relevância da sua atuação no processo de constituição do movimento indígena é sempre citada, seja por lideranças indígenas ao contar sobre as origens do movimento ou por pesquisadores/as que se dedicam a temática da reafirmação étnica na região (CÁRDENAS, 2008; COSTA et al, 2013; IORIS, 2005; MOTA, 2017; PEIXOTO, 2017). Ainda que não tenham a mesma visibilidade que Florêncio Vaz, desde sua fundação, o $\mathrm{GCl}$ é integrado em sua maioria por mulheres. Algumas delas que atuaram nos primeiros anos do movimento são Graça Tapajós, Floriene Vaz, Vera dos Anjos, Irmã Emanuela, Irmã Ivete, e Zenilda Kumaruara. Floriene Vaz, indígena Maytapu, de Pinhel no rio Tapajós, acadêmica de Antropologia na Ufopa, atua no $\mathrm{GCl}$ desde sua fundação:

Eu participei do GRENI e foi depois do GRENI que a gente criou o GCI. São as mesmas pessoas. A gente ia assim muito para a beira do igarapé para fazer ritual, a gente dormia para lá. No dia seguinte a gente fazia aquela memória, né? (...) Toda vez que a gente fazia um ritual, a gente ia para a beira do igarapé. Porque o igarapé tem a força da mãe natureza, da terra, a floresta. A gente ia muito para o meio do rio, o meio da mata. A gente começou a se organizar. A primeira comunidade que pediu para a gente ir lá foi Takuara. (...) Lá a gente fez também essa reunião com a comunidade, a gente até dormiu lá. Cada comunidade que a gente ia, a gente ia para dormir. Porque você vir e voltar no mesmo dia não dava. Então a gente fazia a reunião a tarde e a noite a gente fazia o ritual. Dormia e no dia seguinte voltava embora. Era sempre assim. Depois teve outras comunidades também que começaram a pedir reunião com a gente, elas diziam que queria a gente com eles, que iam pagar passagem para a gente. (...) E a gente ia, porque ninguém tinha grana, né? Quem ia? Era eu e Israel nesse período que viajava para a base. Depois a irmã Emanuela começou a viajar também. Eu lembro também que veio uma menina de Manaus. Elisângela se não me engano. Ela é indígena, ela veio num trabalho pelo curso de nheengatu e ela começou também a participar do $\mathrm{GCl}$ e viajar para as comunidades. Era eu, Israel, essa menina e a irmã Emanuela. A gente dividia. Eu e Israel fomos lá para o finalzinho do Arapiuns e a Irmã Emanuela e a Elisângela para cá para o começo do Arapiuns. A gente se encontrava no meio. No Tapajós também. Lembro que a gente viajou muito. A gente ia para uma comunidade e de lá a gente pegava estrada mesmo, ia andando para outro lugar. Fazia reunião lá. A gente dormia e de manhã pegava rabetinha para outra comunidade. Era assim. A gente visitava várias comunidades. A gente ia na sexta e voltava na segunda-feira. A gente viajava tudinho. 
Voltava e na segunda-feira tinha reunião do $\mathrm{GCl}$ e a gente falava todas as informações que a gente tinha colhido, lá, né? Como foi. Eu acho que isso ajudou muito as comunidades a se assumirem, né? E buscar seus direitos. Eu lembro que eles falavam: Mas como a gente vai voltar a ser índio? Voltar a morar no mato? Mas, espera aí, a gente já mora no mato, né? Não é voltar a ser índio, né? Nós somos indígenas. O problema é que a gente não se reconhece, não se assume, não busca de fato nossos direitos, né? Então, a gente ia para essas reuniões e sempre colocava os direitos indígenas em relação à saúde, demarcação de terra (Entrevista gravada em 26.06.2018, em Santarém/PA).

Graça Tapajós7 7 oriunda de Caridade localizada na Terra Indígena Cobra Grande, no rio Arapiuns, atuou desde o início do o movimento indígena no Baixo Tapajós. Ela relata como era o trabalho do $\mathrm{GCl}$ no final dos anos 1990 :

A gente reunia nas comunidades. Todo mundo falava primeiramente da sua história, da sua origem. Ah, mas eu sou índio, eu tenho minha história. Ah, mas eu tive vergonha, eu quis esconder isso. Escondi. Porque que a gente tinha que esconder? Ai a gente começou também a buscar, né? No meio de todo aquele sentimento que a gente tinha dessa identidade que estava silenciada, a gente passou a despertar para que ela viesse ganhar visibilidade. E foi a partir dai que nós começamos. Com esse desejo que nós nos encontramos com esses bons sentimentos. Na época nós éramos poucos, não éramos tantos. No caso tinha a professora Zenilda, tinham os religiosos, os estudantes. E ai a gente conseguia discutir a nossa identidade, né? Queríamos não ficar apenas naquela discussão, mas o que nós podíamos fazer para isso. E ai foi acontecendo, foi acontecendo. Então decidimos fazer nosso primeiro encontro no Jauarituba. Isso foi em 1997. Mas a essência de tudo isso é que aquele povo sentia essa vontade. Esse desejo que tinha dentro de si. Essa identidade estava ali silenciada. Que quando ela vem assim, as pessoas começaram a dar essa visibilidade. Foi com o encontro de Jauarituba. Nessa virada já tínhamos 11 comunidades que fizeram adesão a essa luta. Quando nós estávamos ali já pontuávamos junto com eles o que eles pensavam, o que eles queriam, o que eles sentiam. Além de ter toda uma história da sua ancestralidade, ali se vinha buscar também o que? Se encontrar com o que? Com a terra, com seu território. O que fazer, como fazer, o que fazer para garantir o direito a terra. (...) A gente seguia fazendo essa jornada. Uma jornada de levante de identidade e foi. Foi e a gente enfrentou muitos obstáculos em relação a essa sociedade ocidental. A gente não baixou a cabeça e foi para o enfrentamento, fazer valer o respeito pelos direitos. E foi assim (Entrevista gravada em 25.06.2018, em Santarém/PA).

À medida que se propagava o entendimento do modo de vida das pessoas que viviam à beira dos rios Tapajós e Arapiuns como indígena, processos de autoafirmação étnica emergiram na região. Um momento emblemático da constituição do movimento indígena no Baixo Tapajós é quando o primeiro grupo de pessoas se afirmou perante as

\footnotetext{
${ }^{7}$ Graça Tapajós é mestre em Direito pela UFPA (MOTA, 2017). Com exceção de Graça, as outras quatro mulheres na época que as entrevistei cursavam graduação na Ufopa.
} 
comunidades vizinhas e perante o Estado enquanto povo indígena. Esse momento, que será brevemente narrado a seguir, pode ser analisado como o acontecimento fundador do movimento na região, no mesmo sentido que Bicalho (2010), ao se basear no conceito de Ricoeur, afirma que as assembleias indígenas nos anos 1970 são o acontecimento fundador do movimento indígena no Brasil 8 .

Em 31 de maio de 1998, período de forte mobilização das lideranças do Baixo Tapajós em defesa do território tradicional, morreu em Takuara, na Floresta Nacional do Tapajós (Flona Tapajós), Laurelino Floriano Cruz, o pajé Laurelino, líder político e curador. Pajé Laurelino, nasceu em 1909, no rio Arapiuns e na adolescência se mudou para Takuara. Laurelino é reconhecido pelos/as habitantes das localidades ribeirinhas no Baixo Tapajós como um pajé poderoso e discípulo do Pajé Merandolino. Esse último é muito prestigiado e tido como "o último grande sacaca de nascença do Arapiuns" (IORIS, 2005). Sacacas são pajés que têm habilidades xamânicas, que nasceram com dom e tem o poder de circular entre o mundo da terra e do fundo. Além disso, quem é sacaca pode se transformar em cobra grande (MAHALEM DE LIMA, 2015, p. 368). pajé Laurelino, segundo relatos, tinha grande poder de cura, loris (2005) escutou depoimento que "É Deus no céu e Laurelino na terra. O que o médico não deu jeito, Laurelino curou" (apud VAZ FILHO, 2016, p. 33). De acordo com narrativa dos filhos e netos de Laurelino, ele "no seu leito de morte expressou seu último desejo que seu povo lutasse pelo reconhecimento de sua origem. Por isso, procuraram a FUNAI em Itaituba" (VAZ FILHO, 2010, p. 232). A explicação nativa da morte do Laurelino como a gênese do movimento indígena no Baixo Tapajós é ainda reproduzida pelas atuais lideranças indígenas. Vaz Filho (2010, p. 406) classifica o falecimento de Laurelino como "o fator aglutinador para Takuara e todas as outras comunidades e aldeias na luta pela demarcação dos territórios". Vaz Filho (2016, p. 37-38) destaca a relevância da pajelança, ao lado da reivindicação pelo direito à terra, no processo de constituição do movimento:

Após a comoção geral provocada pela morte de Laurelino, os moradores de Takuara se assumiram como índios (VAZ FILHO, 2010), e logo ocorreu uma grande expansão do movimento indígena a partir de Takuara. Isso é um sinal da influência dos pajés e da pajelança como uma instituição fundamental para o entendimento da reorganização indígena no oeste do Pará. A pajelança é o principal fornecedor de elementos

\footnotetext{
${ }^{8}$ Ver seção 1, "Institucionalização do movimento indígena no Brasil", desse artigo.
} 
para a construção e afirmação da identidade indígena na região. Por isso, uma vez identificados como povos indígenas, esses grupos destacam a pajelança como parte significativa da sua cultura indígena. E mesmo os demais moradores das comunidades ribeirinhas e cidades no baixo Amazonas continuam com uma cosmovisão em que tem destaque a crença nos pajés (ANJOS, 2008, p. 4).

Com toda simbologia da morte do pajé Laurelino, moradores/as de Takuara enviaram documento à FUNAI solicitando o reconhecimento enquanto indígena? especificamente, como povo Munduruku. Na sequência, vários outros moradores/as da região passaram a se assumir indígenas publicamente, principalmente aquelas residentes no território que, em 06 de novembro de 1998, se tornaria legalmente a Resex TapajósArapiuns. Então, de 31/12/1999 a 01/01/2000, foi organizado o "I Encontro dos Povos Indígenas do Tapajós", em Jauarituba tendo contado com a presença de 150 indígenas. Esse encontro fortaleceu os laços entres as pessoas. Na ocasião, os/as participantes planejaram a recepção daqueles/as que chegariam a Santarém compondo a "Marcha Indígena dos 500 anos". Os/as integrantes da Marcha estavam a caminho da Bahia para participar do ato "Brasil, Outros 500: resistência indígena, negra e popular", que aconteceu em Porto Seguro, em 22 de abril de 2000, em contraponto às comemorações oficiais dos 500 anos do "descobrimento".

Aproximadamente 500 indígenas de diversos povos chegaram no dia 07 de abril de 2000, em Santarém, e foram recebidos/as por centenas de indígenas e simpatizantes. O grupo de visitantes se uniu aos anfitriões e anfitriãs e juntos saíram em passeata pela cidade. Esse ato é um marco, pois foi a primeira manifestação pública, depois de tanto tempo prevalecendo o discurso que os povos indígenas na região estavam extintos, em que parte da população local se assumia indígena. Graça Tapajós relembra esse momento:

Pensa na coisa mais linda quando essa marcha encostou aqui. Eram toques, era uma harmonia de orquestra de instrumentos indígenas que se encontrou onde é a Vera Paz. E lá foi a grande concentração. Foi não só pelo ponto de vista bonito, mas a gente está trazendo essa história, dando essa visibilidade para a cidade. Era imprensa, os apoiadores...

\footnotetext{
${ }^{9}$ Todas as narrativas que me deparei contam que o primeiro passo dos/as moradores/as de Takuara para se reconhecerem enquanto povo Munduruku foi ir à FUNAI pedir documento para serem reconhecidos indígenas. Esse episódio legitimou a ação dos/as familiares do pajé Laurelino. Porém, com o passar do tempo isso mudou. As lideranças se apropriaram das leis e do discurso do autoreconhecimento, ou seja, é indígena quem se reconhece com tal e é reconhecido pelo grupo que se diz pertencer. Assim, gestores/as da FUNAI deixaram de ser demandados/as no sentido de reconhecer a identidade indígena.
} 
Era de admirar. 'Nossa, mas como é que é? Nunca aqui teve índio'. A passeata foi pela avenida Tapajós. O primeiro marco que nós fizemos aqui foi lá na Praça Rodrigues dos Santos, tem um marco lá. Se você quiser dar uma olhada tem uma estatueta de madeira lá. Como sinal de resistência indígena ali. Por quê? Porque bem aqui do lado está a fotografia do Padre Felipe Bettendorff. Está bem lá bonitão. E a onde está a marca dos povos indígenas que não tem na Praça Rodrigues dos Santos? Então lá foi feito um monumento, essa peça de madeira que está lá é histórica. E todo mundo fez um momento lá, celebrado de cantos, de alegria, de pronunciamentos indígenas. Foi feito esse marco. Depois prosseguiu, né? Foi para a área do colégio Dom Amando. Mobilizou a cidade! Foi muito grande, muito bonito (Entrevista gravada em 25.06.2018, em Santarém/PA).

Após a realização do ato público na cidade de Santarém, onze representantes do Baixo Tapajós se juntaram à Marcha até Porto Seguro. Para a maioria dos/as participantes do Baixo Tapajós foi o primeiro contato com lideranças do movimento indígena fora da região de sua origem. Em Porto Seguro, estiveram presentes 03 mil indígenas de 140 povos (VAZ FILHO, 2010, p. 274). O convívio com diferentes povos, mobilizados e engajados em torno de temas que produzem identidades comuns ampliou a percepção do que é ser indígena para os/as representantes do Baixo Tapajós. As lideranças dos povos indígenas do Nordeste tornaram-se uma referência, pois eram pessoas que não se encaixavam no estereótipo do índio puro, mas, ao mesmo tempo, não tinham a menor dúvida quanto ao seu pertencimento étnico ${ }^{10}$. No retorno de Porto Seguro, os/as indígenas bastante motivados/as fundaram o Conselho Indígena Tapajós Arapiuns - CITA, com sede localizada na cidade de Santarém. A intenção das lideranças era criar uma entidade que pudesse representar formalmente os povos indígenas do Baixo Tapajós e também potencializar a articulação política. A criação do CITA não só ampliou e deu institucionalidade para a articulação dos indígenas localmente, mas também conectou os povos do Baixo Tapajós na rede de articulação de lideranças do movimento indígena da Amazônia e do Brasil. Segue narrativa de Graça Tapajós sobre esse processo:

Já estávamos articulando para seguir viagem, né? Era para sair daqui de navio até Belém. De lá pegar o ônibus e nós seguirmos até na Bahia, em Coroa Vermelha. Eu lembro que foi gente de Vila Franca, Takuara, do próprio Jauarituba. Eu sei que foram 11 lideranças. E quem para ir? E agora, para coordenar esse povo? Eu fui eleita. Que eu tinha que ir para acompanhar essa delegação. Então vamos, né? Porque tínhamos que estar organizados. (...) Foi muito boa a ida, o percurso. Quando nós chegamos em Belém foi outra mobilização. Porque lá eles também

\footnotetext{
${ }^{10}$ Sobre relação entre o processo de etnogênese dos povos do Baixo Tapajós e do Nordeste ver Vaz Filho (2010).
} 
estavam preparados para nos receber. Foi muito bonito, muito forte. $\mathrm{Ai}$ nós íamos parando, né? Parando nas cidades. la pegando os indígenas. Olha foi uma coisa assim muito marcante. Eu gostaria que tivesse uma outra marcha. Foi muito linda. Muito mesmo. Esse encontro de povos, encontro de identidades, encontro de sentimentos, de recuperação mesmo para a gente que estava começando a nossa luta. Um evento de aprendizado. De aprendizado, fortalecimento de identidade, afirmação de identidade, enfim. Então, lá já houveram as decepções que era o governo do Fernando Henrique. (...) As bombas que a gente levou lá, a gente corria, era helicóptero marcando a gente por cima e a gente caindo pra dentro d'água lá naquela beirada toda lá. Mas isso trouxe uma coisa muito forte. Tanto que depois teve a criação do CITA, já no retorno, né? A gente veio um pouco cabisbaixo, mas a gente disse "não, a gente vai ter que criar o CITA!". Criar o CITA para ser um Conselho de articulação com as bases, com as comunidades. Esse foi o marco da marcha indígena. Ela trouxe esse fôlego muito grande para o movimento. $E$ isso passou a continuar. Porque a gente era presente nas comunidades. Nas bases. A gente ia, viajava (Entrevista gravada em 25.06.2018, em Santarém/PA).

Com atuação de representantes do CGI e do CITA junto aos comunitários/as bem como a realização de encontros anuais indígenas ocorreu um "crescimento e solidificação de uma autoconsciência cultural e identitária indígena na região" (VAZ FILHO, 2010, p. 314). Ao passo que aumentava a quantidade de pessoas se assumindo como indígenas, os conflitos com aquelas que não se assumiam indígenas começaram a eclodir, tal como conta Auricélia Arapium:

Foi, foi nessa época de 2002 para 2003. Mas os rachas começaram em 2002. Os problemas do movimento. Começou a acontecer uma coisa que eu não entendia, né? O que eu entendia era que o movimento indígena não estava se dando bem com a RESEX. E ai os movimentos sociais racham, vários movimentos sociais. A guerra estava pegando fogo para cá, movimento indígena e RESEX. (...) Ai eu vim para Santarém e resolvo tentar fazer alguma coisa. A [Maria das] Neves era uma grande liderança aqui do movimento. Encontrei Enoque, que é da Vila Franca, e a Neves, nós nos juntamos e falamos: vamos ver o que a gente faz porque não é justo que aqui o movimento indígena e a RESEX fiquem brigando entre si e a gente sofre nas comunidades. Até porque a gente não sabe de fato o que rola, né? E um puxa para o lado e o outro puxa para o outro. Foi ai que a gente sentou com o $\mathrm{GCl}$ e o CITA. Nós tivemos muito apoio na época. Eu me lembro da Graça Tapajós, da própria Vera, do Florêncio. Decidimos marcar uma audiência. Falamos com o Procurador Felício Pontes, né? O Felício Pontes ainda estava aqui no Pará, aqui em Santarém. Ai o Felício se propôs a fazer uma audiência de conciliação. A gente tinha menos de um mês para realizar um evento daquele. $E$ foi nós três das comunidades: era eu, Enoque e Neves. Com apoio do $\mathrm{GCl}$ e do CITA. E agora o que a gente vai fazer? Eu deixei meus estudos de lado. Foi no meio de abril, em 2003. (...) Ai, a gente começou a ir para o rádio. A Rádio Rural também deu muito apoio. Fomos para a Diocese, fomos buscando os movimentos sociais, GDA, FUNAI de Itaituba. Fomos com o próprio IBAMA. Com a própria Tapajoara. Com vários movimentos, tanto os prós quanto os "contra". A gente ia nas escolas pedindo 
ajuda para fazer o encontro. Eu lembro que na época a gente conseguiu um barco para o Arapiuns, um barco para o Tapajós, um barco para a FLONA. Três barcos aqui de Santarém. A gente conseguiu em um mês, pense. $E$ fomos em cada instituição. A gente às vezes ia comer na casa dos padres. A gente chegava de propósito na hora do almoço para a gente poder se alimentar. Eles só faziam os documentos para a gente, a Vera, a Floriene. E se vira. E a gente conseguiu bastante recurso. Eu lembro que a gente conseguiu tanta coisa. Até umas sacolas assim com sapato, com roupa para a gente levar para as aldeias. (...) Teve apoio de muita gente. Mas quem puxou foi eu, a Neves e o Enoque. Parei de estudar e fiquei um mês aqui em Santarém sem conhecer muita coisa. E lá em Vila Franca a gente conseguiu que o Felício fizesse um acordo. Assim, a gente parou mais de brigar, mas assim a gente nunca se deu bem não. O negócio era muito pesado mesmo (Entrevista gravada em 21.06.2018, em Santarém/PA).

As divergências entre lideranças polarizaram o campo de atuação de agentes sociais que representavam entidades não-governamentais e governamentais. Assim, as pessoas que não se assumiam indígenas atuavam em entidades como Conselho Nacional dos Seringueiros - CNS, o Sindicato dos Trabalhadores e Trabalhadoras Rurais - STTR com apoio do então IBAMA, hoje ICMBio. Nesse campo de disputas, a estratégia de lideranças indígenas acionarem o Ministério Público Federal para mediar conflitos ainda hoje é recorrente na região do Baixo Tapajós. Os conflitos no âmbito da gestão do território da RESEX permanecem em curso, embora as alianças e divergências entre agentes sociais tenham se modificado. Nos primeiros anos do século XXI, a possibilidade de demarcação de terras indígenas em parte do território da Resex Tapajós-Arapiuns e da Flona Tapajós foi o catalisador dos desentendimentos. Hoje, os conflitos estão focados no próprio modelo de gestão da RESEX, como, por exemplo, na implantação de projetos por entidades não-governamentais de exploração de recursos madeireiros e não-madeireiros. Lideranças indígenas exigem o cumprimento da consulta prévia, livre e informada, conforme previsto na Convenção $n^{\circ} 169$ da Organização Internacional do Trabalho, antes de iniciar qualquer ação a ser lá desenvolvida. A reivindicação principal é que as pessoas que residem na RESEX sejam efetivamente consultadas e não apenas aquelas poucas que compõem o Conselho Deliberativo. Tal como apontado por Vaz Filho (2010, p. 447), a disputa em jogo envolve distribuição de poder que engloba a classificação étnica, recursos materiais, simbólicos, e poder político.

Assumir publicamente a identidade indígena desencadeia uma reinterpretação das pessoas sobre sua origem, trajetória e práticas culturais. Além disso, segundo en- 
tendimento de indígenas no Baixo Tapajós, diz respeito a firmar um compromisso com lideranças do movimento indígena em relação à participação em reuniões, assembleias, eventos, manifestações públicas e também com contribuição financeira para o CITA. Nos últimos 20 anos, aumentou o número da população na região que se reconhece como indígena perante o Estado e que atua junto ao movimento indígena. De acordo com informações publicadas, em 2014, no "Caderno Nova Cartografia Social: Resistência e Mobilização dos Povos Indígenas do Baixo Tapajós" (PROJETO NOVA CARTOGRAFIA, 2014), no Baixo rio Tapajós tem 13 povos indígenas, que somam uma população de aproximadamente 07 mil pessoas, em 55 aldeias e 16 territórios. Esses dados são circunstanciais visto que há um processo constante de cisão e fusão de aldeias e de pessoas se assumindo indígenas. Assim, essas informações são dinâmicas. O número de aldeias, territórios e população varia com o passar do tempo. De acordo com os registros do CITA, em agosto de 2018, eram 64 aldeias.

Os 13 povos indígenas do Baixo Tapajós, segundo o CITA, são: Apiaká, Arapium, Arara Vermelha, Borari, Cara Preta, Jaraqui, Kumaruara, Maytapu, Munduruku, Tapajó, Tapuia, Tupaiú e Tupinambá. A área de atuação do CITA, definida por suas lideranças abrange os rios Tapajós, Arapiuns e Maró, Eixo Forte e o Planalto Santareno que englobam os municípios de Aveiro, Belterra e Santarém.

Graça Tapajós faz uma reflexão sobre o aumento da população que se assume indígena. Com isso, as lideranças não conseguiram manter uma agenda de trabalho junto aos moradores/as das localidades para promover formação sobre direitos indígenas e repassar informações aos/às militantes mais jovens sobre a luta dos/as indígenas no Baixo Tapajós. Nas palavras dela:

O movimento começa a crescer sem ter formação. Por isso que quando a gente vai indicar uma pessoa para conduzir a luta do movimento, um coordenador do CITA tem que traçar perfil. Não tem como. A luta do movimento, os direitos do movimento, é diferente da luta da sociedade ocidental. Ela é muito além. Quando você vai falar do direito à terra, à identidade. (...) Eu vejo o movimento hoje bem, ainda que a gente saiba que tem seus altos e baixos, mas ele agora trouxe um diferencial. Eu penso que a gente teria que ter formação de consciência, formação de liderança. Ser conhecedores dos direitos dos povos indígenas. Que antes nós fazíamos isso. Isso faz com que possa fortalecer o destino do movimento. Isso é um desafio para o movimento. Tem uma coisa que a gente ainda percebe dentro das comunidades, da base que é o querer. O desejo da autoafirmação da identidade. Precisa focar, trabalhando 
na perspectiva da formação. (Entrevista gravada em 25.06.2018, em Santarém/PA).

As lideranças do CITA fazem um Censo em que as pessoas que se autodeclaram indígenas devem se cadastrar. A importância desse cadastramento é o reconhecimento pela entidade representativa dos indígenas do Baixo Tapajós que aquela pessoa é indígena. Ou seja, as lideranças do movimento atuam politicamente naquelas localidades em que indígenas estão cadastrados/as no Censo do CITA. Mais ainda, gestores/as públicos reconhecem como sujeito de direito para acessar políticas públicas específicas para povos indígenas apenas aquelas pessoas que têm seus nomes cadastrados na lista do CITA. Por exemplo, só foram incluídos/as no cadastro da Secretaria Especial de Saúde Indígena do Ministério da Saúde os/as indígenas que estão no Censo do CITA e, apenas as pessoas cadastradas, são beneficiárias da Política Nacional de Atenção à Saúde dos Povos Indígenas.

Há um debate constante entre lideranças, sobre os critérios para o cadastramento indígena. Tais critérios são parte da estratégia para incentivar as pessoas se engajarem no movimento e contribuírem com a luta dos povos indígenas. As lideranças concordam sobre a necessidade em promover atividades regulares com os/as moradores/as das aldeias para que haja legitimidade na representação por elas exercida e um entendimento comum sobre as reivindicações e estratégias de intervenção dos/as indígenas junto aos agentes públicos. Nas palavras de Luana Kumaruara:

Às vezes a comunidade não faz parte porque eles não sabem de que
fazer parte, né? (...) Isso eu tiro pela experiência da época do CITA. A
gente só conseguiu fortalecer nossas mobilizações aqui porque estava
tendo formação de base. As formações de base são muito importantes.
Porque tudo balança ali, eles vêm para as ações na cidade com toda
certeza do que eles estão reivindicando, né? (Entrevista gravada em
23.06.2018, em Santarém/PA).

Lideranças insistem que só com ação política e enfrentamento é possível conseguir atendimento por parte dos/as agentes do Estado às demandas apresentadas pelos/as indígenas. Por isso, nos últimos 05 anos, a estratégia de ocupação de prédios públicos é acionada pelos/as indígenas no Baixo Tapajós. Já foram ocupados os prédios do Ufopa, Justiça Federal, ICMBio, SESAI, Prefeitura Municipal e funcionários/as da FUNAI/Brasília e do Ministério da Justiça já foram detidos em Santarém por lideranças 
do movimento que reivindicavam publicação de relatório de identificação de delimitação de terra indígena na região ${ }^{11}$. Todas essas intervenções foram, na avaliação de Luana Kumaruara, bem sucedidas. Isso porque, após a pressão dos/as indígenas houve por parte dos agentes públicos atendimento de reivindicações apresentadas.

Um fator determinante na adesão a esse tipo de estratégia é a entrada massiva de indígenas no Baixo Tapajós na Universidade. Desde 2010, a Ufopa, realiza Processo Seletivo Especial (PSE) para Indígenas com reserva de vagas específicas em todos os cursos regulares de graduação. Hoje, são aproximadamente 300 discentes indígenas do Baixo Tapajós na Ufopa ${ }^{12}$ que recebem bolsa de estudo. Com isso, aumentou a população indígena residindo na cidade, com renda e com acesso a diferentes tipos de conhecimentos promovidos tanto pelos estudos formais quanto pela circulação no ambiente urbano (ARANTES, 2017). Essa dinâmica influenciou diretamente na própria composição da coordenação do Conselho Indígena Tapajós Arapiuns - CITA, que, desde então, passou a ter sempre entre seus quadros estudantes indígenas da Ufopa. Luana Kumaruara fala sobre a participação dos/as universitários/as no movimento:

\begin{abstract}
Os mais velhos estavam muito nessa de apostar na juventude. Eu, João, lanuzy entramos jovens no CITA para assumir esses cargos, né? Sempre acreditaram. Eles acham que é importante de ter a base e ter também a juventude para ter esse jogo de cintura de documento, na questão burocrática, de ser ágil. E os acadêmicos começam a ocupar esse espaço dentro do Conselho. Na minha gestão era todo mundo acadêmico. Era lanuzzy, Diego, eu e Abmael, todos eram acadêmicos (Entrevista gravada em 23.06.2018, em Santarém/PA).
\end{abstract}

Acadêmicos indígenas tornaram-se uma categoria, social no jogo político, reconhecida no âmbito do chamado movimento indígena no Baixo Tapajós. Essa nova categoria é detentora de recursos simbólicos e materiais marcantes da sociedade ocidental. As lideranças mais antigas cobram que esses/as estudantes atuem para garantir a meIhoria na qualidade de vida dos/as indígenas, principalmente, naqueles/as que vivem nas aldeias. Mesmo que grande parte desses/as discentes não participe de atividades políticas, há um grupo de pessoas muito atuante. E alguns/as relatam que se torna-

\footnotetext{
${ }^{11}$ Todas essas ocupações foram realizadas entre 2014 e 2018 motivadas pela efetivação do direito à autoafirmação e a demarcação das terras (Justiça Federal), do direito à saúde (SESAI), pela reivindicação por bolsas de estudo (Ufopa), protesto contra implementação de projeto de crédito carbono na RESEX (ICMBio) e contra construção de portos no Lago do Maicá no Planalto Santareno (Prefeitura de Santarém).

${ }^{12}$ Fonte: Cadastro PROGES/Ufopa do Programa Bolsa Permanência/MEC, 2017.
} 
ram lideranças indígenas a partir da vivência na universidade, como Luana Kumaruara. Outras pessoas retomaram e intensificaram a militância depois que ingressaram no ensino superior, como Auricélia Arapium. O papel exercido por essa juventude indígena universitária militante proporcionou mudanças na dinâmica de atuação dos/as indígenas do Baixo Tapajós tanto em escala local, quanto regional (Amazônia) e nacional (Brasil) (VAZ FILHO ET AL, 2017). Culminando em uma maior participação em eventos e instâncias de representação, sejam articulados por organizações indígenas, indigenistas ou governamentais.

Há outra categoria social que tem atuação no âmbito do movimento indígena no Baixo Tapajós que tem semelhanças com o papel exercido por acadêmicos/as: são os/as professores/as das escolas indígenas. A efetivação da educação diferenciada na região se deu na primeira década do século XXI e esse processo originou essa categoria profissional. Essas pessoas são socialmente reconhecidas por serem detentoras de conhecimento diferente daquele que tradicionalmente é legitimado entre indígenas. Além disso, com as escolas funcionando nas aldeias, a circulação de dinheiro aumentou significativamente. As relações entre as pessoas que lideram essas categorias - no caso, acadêmicos/as e professores/as - são permeadas por tensões e disputas. A abordagem aqui proposta não tem como foco esses conflitos entre lideranças do movimento, mas, posteriormente, é uma reflexão que pode contribuir para o próprio entendimento do conceito nativo de movimento indígena no Baixo Tapajós. Visto que, como já referenciado, há uma disputa em jogo protagonizada por representantes dessas categorias que problematiza a compatibilização das diferentes lógicas, no caso, lógica indígena e lógica dos brancos, nas tomadas de decisão e nos modos de ação das lideranças. Nota-se que são exatamente as pessoas que têm maior domínio na mediação entre esses universos sociais - professores/as e acadêmicos/as - que estão no centro dessa disputa.

\section{Considerações finais: sobre vozes indígenas femininas}

A reflexão aqui apresentada, mesmo que de forma embrionária, evidencia algumas questões a respeito do processo de constituição do movimento indígena no Baixo Tapajós. As narrativas dessas cinco mulheres indígenas de povos e trajetórias distintas demonstram como a vida social é construída a partir de experiências reais em que os/as 
agentes lidam o tempo todo com conflitos, imprevistos, relações de poder. A construção da ordem social não é unidade perfeita. Esse processo é dinâmico, datado e situado (NEVES, 2018, p. 19).

Expor sobre o processo de constituição do movimento indígena no Baixo Tapajós a partir do olhar de mulheres indígenas potencializa a análise das relações sociais enquanto representações e transformações do mundo. Essas mulheres exerceram e exercem papéis estratégicos nas ações políticas, ainda que sejam pouco reconhecidos socialmente. Em algumas situações elas são, inclusive, maioria numérica, como por exemplo, no $\mathrm{GCl}$. O GCl enquanto instituição tem seu papel reconhecido pelas lideranças indígenas, mas é frequentemente referenciado na figura do frei Florêncio, ainda que o grupo sempre tenha sido constituído em sua grande maioria por mulheres. Em relação à entidade representativa dos/as indígenas - o CITA, as mulheres sempre estiveram, como diz Fabiana Borari, "nos bastidores segurando as pontas". Apenas uma vez foi eleita uma coordenadora mulher, mas ela renunciou antes da primeira metade do mandato.

É de se destacar que essas lideranças femininas remetem sempre a outras muIheres enquanto inspiração para a luta pelos direitos indígenas, como explicitado por Fabiana Borari:

\begin{abstract}
A minha vinda para o movimento foi sempre acompanhando o movimento de resistência da minha mãe (...). Você observa que são sempre as mulheres que estão a frente no Curucurui. Poucas e raras vezes aparecerá um homem, é mais mulher. Que está na frente no Curucuruí. $\mathrm{Na}$ associação, no cacicado, nas organizações, nos eventos que acontecem lá dentro, sempre são as mulheres que estão organizando. Sempre foi assim. Desde que eu me entendi por guria eram as mulheres que puxavam as histórias. As histórias que a gente tem sempre são contadas com a versão da mulher (Entrevista gravada em 26.06.2018, em Santarém/PA).
\end{abstract}

Luana Kumaruara aponta que "Eu venho de uma linhagem sempre falo matriarcal, Kumaruara. Que é de mulheres mesmo, por parte da minha mãe, por parte da minha avó. E da minha bisavó". Auricélia Arapium afirma que começou a militar em movimentos sociais "seguindo os passos de minha mãe". Essas três mulheres são mães e suas crianças sempre as acompanham nas atividades cotidianas. É comum entre elas o uso da expressão "nossos filhos são criados dentro do movimento". Essas mulheres vivem diariamente dilemas para conciliar os papeis de mãe, liderança e estudante universitária. 
As mulheres indígenas estão ampliando suas ações políticas no âmbito do CITA. Em 2017, elas organizaram três encontros regionais de mulheres contemplando as regiões dos rios Tapajós, Arapiuns e Planalto Santareno que contou com a participação de cerca de 250 indígenas ${ }^{13}$. Para viabilizar financeiramente a realização dos encontros, as mulheres escreveram projeto, em nome do CITA, que foi submetido a edital de uma organização não governamental sem fins lucrativos. Em continuidade a esse processo, em setembro de 2018, acontecerá a $1^{\circ}$ Assembleia das Mulheres Indígenas do Baixo Tapajós. Um dos objetivos é eleger uma coordenação para reativar o Departamento de Mulheres do $\mathrm{CITA}^{14}$. Esses processos de mobilização provocam fortalecimento da rede de apoio entre as mulheres e do fomento às atividades produtivas como, por exemplo, a fabricação de remédios caseiros e produtos de limpeza.

A participação das mulheres indígenas em papéis políticos de maior visibilidade no âmbito do movimento indígena no Baixo Tapajós vem se ampliando. Esse processo está em curso e é permeado por tensões que envolvem, entre outros aspectos, questões de gênero. Luana Kumaruara relata que quando começou a trabalhar com as mulheres nas aldeias, em 2017, não tinha noção da responsabilidade e que estava "mexendo num ninho de formigueiro mesmo", pois várias denúncias de casos de violência doméstica começaram a surgir. Além disso, ela e outras lideranças começaram a ser alvo de ofensas por parte de militantes indígenas homens. Essas questões são ainda pouco debatidas, inclusive no meio acadêmico (SACCHI; GRAMKOW, 2012; VERDUM, 2008).

A partir da reflexão aqui apresentada, ficou explicita a participação determinante das mulheres no processo de constituição do movimento indígena no Baixo Tapajós e, ao mesmo tempo, surgem novos caminhos a serem trilhados no intuito de, por meio das vozes indígenas femininas, analisar o papel dessas lideranças enquanto agentes mediadoras de universos sociais.

\footnotetext{
${ }^{13}$ Informação levantada a partir das listas de presença dos encontros.

${ }^{14} \mathrm{~A}$ Assembleia foi realizada e foram eleitas mulheres para compor o Departamento de Mulheres do CITA. Depois, em janeiro de 2019, foi realizado o I Encontrão de Mulheres do Baixo Tapajós, na aldeia Novo Gurupá, rio Arapiuns com participação de aproximadamente 200 pessoas.
} 


\section{Referências}

BICALHO, Poliene Soares dos Santos. As Assembléias Indígenas - O advento do movimento indígena no Brasil. In: Revista OPSIS. Catalão: v. 10, n. 1, 2010, p. 91-114.

CÁRDENAS, Omaira Bolaños. Constructing Indigenous Ethnicities and Claiming Land Rights in the Lower Tapajós and Arapiuns Region, Brazilian Amazon. Tese de Doutorado apresentada na Universidade da Flórida (EUA), 2008. 287 p.

COSTA, Solange Maria Gayoso da; VIEIRA, Judith Costa; LIMA, Marcos Vinicius Costa; MILEO, Bruno Paracampo. Territorialização e identidade indígena no baixo Tapajós no estado do Pará. In: VI Jornada Internacional de Políticas Públicas. São Luis: UFMA, 2013.

INSTITUTO BRASILEIRO DE GEOGRAFIA E ESTATÍSTICA. Censo Demográfico 2010. Disponível em: http://censo2010.ibge.gov.br/. Acesso em 27/06/2017.

IORIS, Edviges Marta. A Forest of Disputes: Struggles over Spaces, Resources and Social Identities. Tese de Doutorado. Gainesville, Flórida: UF, 2005, 326 p.

LUCIANO, Gersem José dos Santos. O Índio Brasileiro: o que você precisa saber sobre os povos indígenas no Brasil de hoje. Brasília: Ministério da Educação; LACED/Museu Nacional, 2006.

MAHALEM DE LIMA, Leandro. No Arapiuns, entre verdadeiros e -ranas: Sobre as lógicas, as organizações e os movimentos dos espaços do político. Tese de Doutorado. São Paulo: USP, 2015. 439 p.

MOTA, Maria das Graças Tapajós. Povo Tapajó e o território Cobra Grande: entre o direito negado e o direito à terra. Dissertação de Mestrado. Belém: UFPA, 2017, 183 p.

NEVES, Delma Pessanha. Mediação social e mediadores políticos. In: NEVES, Delma Pessanha (org.). Desenvolvimento social e mediadores políticos. Porto Alegre: UFRGS editora, 2008. p. 17-41.

PACHECO DE OLIVEIRA, João. O nascimento do Brasil e outros ensaios: "pacificação", regime tutelar e formação de alteridades. Rio de Janeiro: Contracapa. 2016. 384 p.

PEIXOTO, Kércia Priscilla Figueiredo. "EU EXISTO": afirmação indígena e nomeação do racismo. Os Borari e os Arapium da Terra Maró, Amazônia. Tese de Doutorado. Belém: UFPA, 2017, $287 \mathrm{p}$.

PROJETO NOVA CARTOGRAFIA. Caderno nova cartografia social: resistência e mobilização dos povos indígenas do baixo tapajós. $n^{\circ} 1$ (junho, 2014). Manaus: UEA Edições, 2014.

SACCHI, Ângela; GRAMKOW, Márcia Maria. (Orgs.). Gênero e povos indígenas: coletânea de textos produzidos para o "Fazendo Gênero 9"e para a "27ª Reunião Brasileira de Antropologia". Rio de Janeiro, Brasília: Museu do Índio/GIZ/ FUNAI, 2012.

SILVA, David Junior de Souza. movimento indígena Latino-Americano: Uma Primeira Revisão Da Literatura. In: Rev. Geogr. Acadêmica v.10, n.2, 2016, p. 154-163.

SOUZA LIMA, Antonio Carlos de; HOFFMANN, Maria Barroso; PERES, Sidnei Clemente. Notas sobre os Antecedentes Históricos das Idéias de "Etnodesenvolvimento" 
e de "Acesso de Indígenas ao Ensino Superior" no Brasil. s/d. Disponível em: http://www.trilhasdeconhecimentos.etc.br/artigos/arquivos/Texto_Etnodesenvolvimento_ e_Ensino_Superior_Indigenas.pdf Consulta em: 15/11/2017.

VAZ, Florêncio Almeida. Pajés, Benzedores, Puxadores e Parteiras: os imprescindíveis sacerdotes do povo na Amazônia. Santarém, UFOPA, 2016. 138 p.

. A emergência étnica de povos indígenas no baixo rio tapajós, Amazônia. Tese de Doutorado. Salvador: UFBA, 2010, 478 p.

VERDUM, Ricardo (org.). Mulheres Indígenas, Direitos e Políticas. Brasília: INESC, 2008. 